\title{
Academic Goals and Learning Quality in Higher Education Students
}

\author{
Antonio Valle ${ }^{1}$, José C. Núñez ${ }^{2}$, Ramón G. Cabanach ${ }^{1}$, Julio A. González-Pienda ${ }^{2}$, \\ Susana Rodríguez ${ }^{1}$, Pedro Rosário ${ }^{3}$, María A. Muñoz-Cadavid ${ }^{4}$, and Rebeca Cerezo ${ }^{2}$ \\ ${ }^{1}$ Universidad de A Coruña (Spain) \\ ${ }^{2}$ Universidad de Oviedo (Spain) \\ ${ }^{3}$ Universidade do Minho (Portugal) \\ ${ }^{4}$ Universidad de Santiago de Compostela (Spain)
}

\begin{abstract}
In this paper, the relations between academic goals and various indicators that define the quality of the learning process are analyzed. The purpose was to determine to what extent high, moderate, or low levels of academic goals were positively or negatively related to effort regulation, the value assigned to academic tasks, meta-cognitive self-regulation, self-efficacy, beliefs about learning control, and management of time and study environment. The investigation was carried out with a sample of 632 university students (70\% female and 30\% male) and mean age of 21.22 $(\mathrm{SD}=2.2)$.The results show that learning goals, or task orientation, are positively related to all the indictors of learning quality considered herein. Although for other kinds of goals-work-avoidance goals, performance-approach goals, and performance-avoidance goals—significant relations were not found with all the indicators, there was a similar tendency of significant results in all cases; the higher the levels of these goals, the lower the levels of the indicators of learning quality.

Keywords: academic goals, learning quality, higher education
\end{abstract}

\begin{abstract}
En este trabajo se analizan las relaciones de las metas académicas con varios indicadores que definen la calidad del proceso de aprendizaje. Se trata de comprobar hasta qué punto el tener niveles altos, moderados o bajos en las metas académicas se relaciona positiva o negativamente en la regulación del esfuerzo, en el valor asignado a las tareas académicas, en la autorregulación metacognitiva, en la autoeficacia, en las creencias de control y en la gestión del tiempo y ambiente de estudio. La investigación se llevó a cabo con una muestra de 632 estudiantes universitarios (70\% mujeres y $30 \%$ hombres) con una edad media de $21.22(\mathrm{SD}=2.2)$. Los resultados encontrados demuestran que las learning goals, o de aproximación a la tarea, se encuentran relacionadas positivamente con todos los indicadores de calidad del aprendizaje contemplados. En los otros tipos de metas -work-avoidance goals, performance-approach goals and performanceavoidance goals-, aún no habiendo una relación significativa con todos los indicadores, la tendencia de los resultados significativos es la misma en todos los casos, cuanto más altos son los niveles de estas metas, más bajos son los niveles indicadores de calidad del aprendizaje. Palabras clave: metas académicas, calidad del aprendizaje, educación superior
\end{abstract}

This work was funded by the Ministerio de Educación y Ciencia (Project: SEJ2006-01518, Project: EA2007-0242).

Correspondence should be addressed to: Antonio Valle, Departamento de Psicología Evolutiva y de la Educación, Universidad de A Coruña, Campus de Elviña s/n, 15071 A Coruña, Spain. E-mail: vallar@udc.es

How to cite the authors of this article: Valle, A., Núñez, J.C., Cabanach, R.G., González-Pienda, J.A., Rodríguez, S., Rosario, P., Muñoz-Cadavid, M.A., Cerezo, R. 
The concept of Self-Regulated Learning (SRL) integrates research on learning strategies, meta-cognition, learning goals, and, obviously, students' motivation (Lens \& Vansteenkiste, 2008; Valle et al., 2007). Therefore, SRL can be defined as an active process in which students establish the goals that direct their learning, attempting to monitor, regulate, and control their cognitions, motivation, and behaviors in order to achieve these goals.

The studies from cognitive psychology were concerned with the analysis of the strategies used by students in the acquisition, storing, and recall of information, and the differences between "experts" and "novices" in these strategies, without taking motivational variables into account (students as motivationally inert subjects). On the other hand, the studies on motivational variables conceived of students as cognitively empty (Pintrich, Brown, \& Weinstein, 1994). Although some precursor studies with an integrative conception of the cognitive and motivational variables can be found in the $70 \mathrm{~s}$ with Bloom's theory of learning, in the 80 s and the $90 \mathrm{~s}$, both lines of research merge. Interest is aroused because of the results of various studies in which it is observed that motivation affects the cognitive functions and that, in turn, training in cognitive strategies affects certain motivational variables such as self-efficacy, intrinsic motivation, etc. (e.g., Dweck, 1986). This aspect is especially assumed with the studies of Paul Pintrich and his collaborators, who begin to integrate both components within the framework of SRL.

Thus, the exclusively cognitive models cannot explain why some students who seem to have prior knowledge and the necessary strategies do not use them when performing certain tasks, whereas the exclusively motivational models assume that students who have a positive motivational orientation will be more involved and will persist, which will lead them to satisfactory results. However, motivation alone cannot explain the use of adequate or inadequate strategies that affect the achievement level reached. With the perspective of SRL, the interactions of motivation and cognition in academic learning are increasingly integrated and acknowledged.

From these premises, many investigations and theoretical approaches to SRL have appeared, but all of them share an integrative conception of learning that emphasizes the need to combine the cognitive, meta-cognitive, and affectivemotivational components, taking into account the context and behavior of the person who is learning (Zimmerman \& Schunk, 2008). They also share a viewpoint of students as promoters of their learning and their achievement, insofar as they are the regulators of their information processing (thanks to the use of cognitive and meta-cognitive strategies), their motivation, and their observable behavior, and they play an active and constructive role as information seekers, generators, and processors. The results of the investigations carried out under this perspective indicate that students who are considered competent at the self-regulation level establish specific short-term goals, and prioritize their goals adequately (Zimmerman, 2008).
In the last two decades, the outlook of achievement goals has become one of the main theoretical proposals within the study of academic motivation (Anderman \& Wolters, 2006; Elliot, 2005; Meece, Anderman, \& Anderman 2006). Most of the research on academic goals focused initially on two kinds of goals: (a) performance goals (also called selfcentered goals), which center showing one's competence with regard to others; and (b) learning goals (also called mastery or task-oriented goals), which are directed at developing competence and mastery of the tasks (Valle et al., 2007).

Reviewing the differentiation between learning goals and performance goals, Elliot and collaborators (Elliot, 1999; Elliot \& Church, 1997; Elliot, McGregor, \& Gable 1999) proposed a three-dimensional framework for academic goals. In this proposal, in addition to learning goals, they differentiate two performance goals: (a) performanceapproach goals, focused on achieving competence with regard to others; and (b) performance-avoidance goals, aimed at avoiding incompetence with regard to others. Various studies have provided empirical findings that support this distinction within performance goals (e.g., Middleton \& Midgley, 1997; Rodríguez et al., 2001; Skaalvik, 1997; Valle, Cabanach, Rodríguez, Núñez, \& González-Pienda 2006; Wolters, Yu, \& Pintrich, 1996).

Just as the differentiation in approach and avoidance components has been proposed for performance goals, some authors suggest extending this same differentiation to learning goals (Elliot, 1999; Pintrich, 2000a, 2000b). So, it is considered that if learning goals are characterized by high engagement in the task and academic work, in theory, an avoidance tendency in such goals should reflect avoidance of this engagement. Hence, students who pursue a workavoidance goal could be characterized by their avoidance of putting in effort to do well, doing only the bare minimum to get by and avoiding challenging tasks.

In general, learning goals are associated with a large quantity of positive results in diverse motivational, cognitive, and achievement outcomes, whereas performance goals have been linked to less adaptive outcomes, or even to negative outcomes.

So, a large number of studies conclude that learning goals are related to higher self-efficacy (e.g., Bandalos, Finney, \& Geske, 2003; Middleton \& Midgley, 1997; Skaalvik, 1997), stronger beliefs about task value (e.g., Harackiewicz, Barron, \& Elliot, 1998; Wolters et al., 1996), better time and effort management (e.g., Pintrich, Marx, \& Boyle, 1993), more use of meta-cognitive strategies (Middleton \& Midgley, 1997; Wolters et al., 1996), more task involvement (Harackiewicz, Barron, Tauer, Carter, \& Elliot, 2000), and more persistence (Harackiewicz, Barron, Pintrich, Elliot, \& Thrash, 2002; Wolters, 2004). This implies that some of the parameters that best define optimum learning are associated with higher levels of learning goals or task orientation. 
However, the conclusions about the advantages or disadvantages of adopting performance goals are not so clear, as the results vary a lot from one study to another. Thus, some studies (e.g., Middleton \& Midgley, 1997; Wolters, 2004) indicate that the avoidance component of performance goals does not seem to be related to the use of learning strategies. In contrast, whereas the relation between the approach component of performance goals and cognitive strategies is positive for secondary students (Wolters et al., 1996), a relation between performanceapproach goals and the use of self-regulation strategies has been found in some studies (Wolters et al., 1996) but not in others (Middleton \& Midgley, 1997; Wolters, 2004). In a review of 41 articles in which performance-approach goals appeared, Elliot and Moller (2003) found that these goals are positively related to variables such as effort, performance aspirations, performance attainment, self-efficacy, and superficial processing, among others. In contrast, they are not related to variables such as avoidance of help-seeking, deep processing, self-handicapping, and self-regulated learning, among others.

Lastly, as in the case of learning goals, the data provided by studies that analyze the relation between learning and work-avoidance goals is quite consistent. Students with a work-avoidance motivational orientation make a special effort to avoid engaging in any situation that involves a threat to their self-esteem (Nicholls, Patashnick, \& Nolen, 1985). In most of the studies carried out (e.g., Brdar, Rijavec, \& Loncaric, 2006; Dupeyrant \& Mariné, 2005), workavoidance goals have negative relations with the use of deep processing strategies and positive relations, or no relation, with the use of superficial processing strategies. In the study of Harackiewicz, Barron, Carter, Letho, and Elliot (1997), students who had work-avoidance goals obtained the worst academic outcomes. The harmful effects of work-avoidance goals also appear in other studies (e.g., Archer, 1994; Nicholls et al., 1985).

Taking into account that the diverse studies about the benefits or disadvantages of performance goals are somewhat contradictory, some authors consider that their effects on motivation and learning are more complex and deserve more theoretical and empirical attention (Utman, 1997). In any case, as there are still discrepancies about the consequences of adopting a certain kind of goals, especially in the case of performance goals, the purpose of this paper is to analyze the relation of academic goals with various indicators that define the quality of the learning process.

Finally, there are not many papers on the study of academic goals that consider the variable gender, and the available empirical data about the relations between these variables offers a rather confused picture as the results vary a lot from one study to another (Anderman \& Young, 1994; Greene, DeBacker, Ravindran, \& Knows, 1999; Meece \& Jones, 1996; Middleton \& Midgley, 1997). However, in general, the results indicate, on the one hand, that girls are more oriented toward learning than boys and that boys show more predominance of performance-avoidance goals (e.g., Brdar et al., 2006; Meece, Glienke, \& Burg, 2006) and, on the other hand, that boys present higher levels of workavoidance goals than do girls (e.g., Brdar et al., 2006; Thorkildsen \& Nicholls, 1998).

Therefore, the aim of this paper is to examine the relation between achievement goals and indicators of the quality of self-regulated learning such as the persistence in tasks despite difficulties, the interest in academic tasks, the degree of awareness, knowledge, and control over their study activities, and over their time and study environment; self-confidence and confidence to control one's own learning processes. Specifically, from the perspective of an extensively used methodology, we attempt to check the extent to which students' high, moderate, or low levels of learning goals, performance-approach goals, performanceavoidance goals and work-avoidance goals will positively or negatively relate to their effort regulation, the value they assign to academic tasks, their meta-cognitive selfregulation, self-efficacy, and beliefs about control over learning, and their management of time and study environment, in all cases, controlling the possible effect of the variable gender, including it as a covariate within the multivariate analyses (MANCOVAs).

\section{Method}

\section{Participants}

The sample is made up of 632 university students $(70 \%$ females and $30 \%$ males). Of the total sample, $75 \%$ were in the first cycle $\left(1^{\text {st }}, 2^{\text {nd }}\right.$, and $3^{\text {rd }}$ academic years $)$ and the remaining $25 \%$ were in the second cycle $\left(4^{\text {th }}\right.$ and $5^{\text {th }}$ academic years). More specifically, $21.4 \%$ were in the first year, $26.5 \%$ in the second year, $27.1 \%$ in the third year, $11.1 \%$ in the fourth year, and $13.9 \%$ in the fifth year. The mean age of the participants is $21.22(S D=2.2)$

\section{Variables and Measuring Instruments}

Academic goals. To measure academic goals, we used the Goal Orientation Scale, proposed by Skaalvik, (1997), which is made up of 22 items, and differentiates four factorial dimensions that correspond to four types of motivational orientations: (a) task orientation, or learning goals (Cronbach's alpha $=.85 ; 6$ items); (b) avoidance orientation, or work-avoidance goals (Cronbach's alpha = $.73 ; 4$ items); (c) self-enhancing ego orientation, or performance-approach goals (Cronbach's alpha $=.89 ; 5$ items); and (d) self-defeating ego orientation, or performanceavoidance goals (Cronbach's alpha $=.90 ; 6$ items). The students responded to each item of the questionnaire on a Likert-type scale, ranging from 1 (never) to 5 (always). 
Indicators of learning quality. As indicators of learning quality, we used the dimensions of the Motivated Strategies Learning Questionnaire (MSLQ; Pintrich Smith, Garcia, and McKeachie, 1991) that were nearest to the parameters that define constructive and self-regulated learning. According to the main characteristics that define self-regulated learners, some of the MSLQ dimensions provided a good approximation to what optimum learning should be. In this article, we contemplated the following dimensions: (a) effort regulation (Cronbach's alpha $=.75 ; 4$ items), which measures the degree to which students persist in tasks despite difficulties; task value (Cronbach's alpha $=.81 ; 6$ items), which measures the degree to which students consider academic tasks and activities important, interesting, and useful; (b) meta-cognitive self-regulation (Cronbach's alpha $=.81 ; 8$ items), which assesses students' degree of awareness, knowledge, and control over their study activities; (c) self-efficacy for learning and performance (Cronbach's alpha $=.84 ; 8$ items), which measures students' beliefs about their capacities to achieve a good performance; (d) control-of-learning beliefs (Cronbach's alpha $=.68 ; 4$ items), which measures the strength of student's belief in their control over their own learning processes; and (e) time and study environment management (Cronbach's alpha $=.70 ; 8$ items), which measures students' degree of organization of their time and study environment. Although the responses to the items of the MSLQ were originally made on a 7-point Likert scale, we adapted this format to a 5-point scale so that all the variables analyzed would have the same response format. Hence, participants responded to all the items that comprise the indicators of learning quality on a scale ranging from 1 (never) to 5 (always).

\section{Procedure}

The data of the variables of interest were collected on several degrees. The questionnaires were administered in a single session by specialized personnel who collaborated in the investigation. The participants, who completed the questionnaires individually and with no time limit, were reminded that it was very important for them to respond sincerely to the diverse issues.

Taking into account that the main goal of this paper is to determine the differences in some parameters that define learning quality among students with different academic motivations, initially, we established the following three motivational groups using the scores corresponding to percentiles 25, 50, and 75 in each academic goal: (a) low goals-raw score equal to or lower than the score corresponding to percentile 25; (b) moderate goals-raw score between scores corresponding to percentiles 25 and 75; and (c) high goals - raw score equal to or higher than the score corresponding to percentile 75 (see Table 1)

Table 1

Means and standard deviations of the three motivational groups

\begin{tabular}{lcccccccccc}
\hline & \multicolumn{3}{c}{ Low Goals } & & \multicolumn{3}{c}{ Moderate Goals } & \multicolumn{3}{c}{ High Goals } \\
\cline { 2 - 10 } & $M$ & $S D$ & $N$ & $M$ & $S D$ & $N$ & $M$ & $N$ & $N$ \\
\hline Learning Goals & 2.92 & 0.61 & 186 & 3.92 & 0.18 & 265 & 4.58 & 0.21 & 181 \\
Work-Avoidance Goals & 2.11 & 0.45 & 196 & 3.08 & 0.27 & 277 & 4.27 & 0.43 & 159 \\
Performance-Approach Goals & 1.13 & 0.16 & 186 & 2.05 & 0.30 & 278 & 3.46 & 0.61 & 168 \\
Performance-Avoidance Goals & 1.36 & 0.33 & 159 & 2.25 & 0.19 & 162 & 3.43 & 0.67 & 312 \\
\hline
\end{tabular}

Table 2

Means, standard deviations, skewness, kurtosis and correlations of the study variables

\begin{tabular}{|c|c|c|c|c|c|c|c|c|c|c|c|c|c|c|}
\hline & $M$ & $S D$ & Skew. & Kurt. & 1 & 2 & 3 & 4 & 5 & 6 & 7 & 8 & 9 & 10 \\
\hline 1. Learning Goals & 3.81 & .73 & -1.06 & 1.63 & - & & & & & & & & & \\
\hline 2. Work-Avoidance Goals & 3.08 & .89 & .14 & -.17 & $-.21 * *$ & - & & & & & & & & \\
\hline 3. Performance-Approach Goals & 2.15 & .96 & .81 & .20 & $-.25^{* *}$ & $.09 *$ & - & & & & & & & \\
\hline 4. Performance-Avoidance Goals & 2.60 & 1.00 & .31 & -.46 & $-.16^{* *}$ & $.12^{* *}$ & $.33^{* *}$ & - & & & & & & \\
\hline 5. Effort Regulation & 3.39 & .68 & -.33 & .63 & $.38 * *$ & $-.28 * *$ & $-.10^{*}$ & -.05 & - & & & & & \\
\hline 6. Task Value & 3.38 & .62 & -.53 & 1.55 & $.53^{* *}$ & $-.25 * *$ & $-.18 * *$ & $-.09 *$ & $.35 * *$ & - & & & & \\
\hline 7. Meta-cognitive Self-Regulation & 3.44 & .50 & -.52 & 1.76 & $.49 * *$ & $-.26 * *$ & $-.19 * *$ & $-.12 * *$ & $.57 * *$ & $.47^{* *}$ & - & & & \\
\hline 8. Self-Efficacy for Learning and Performance & 3.31 & .58 & -.18 & .87 & $.37^{* *}$ & $-.14 * *$ & -.02 & $-.23 * *$ & $.24 * *$ & $.40^{* *}$ & $.35^{* * *}$ & - & & \\
\hline 9. Control Beliefs & 3.46 & .63 & -.36 & 1.15 & $.30^{* *}$ & -.02 & $-.09 *$ & $-.11 * *$ & $.10^{* *}$ & $.35^{* *}$ & $.25 * *$ & $.46^{* *}$ & - & \\
\hline 10. Time and Study Environment Management & 3.43 & .53 & -.44 & .77 & $.38^{* *}$ & $-.25 * *$ & -.07 & -.00 & $.66^{* *}$ & $.35^{* *}$ & $.56 * *$ & $.21 * *$ & $.09 *$ & - \\
\hline
\end{tabular}

$* \mathrm{p}<.05 . * * \mathrm{p}<.01$. 
In order to determine the possible differences among these three groups in the indicators of learning quality, while controlling the effect of the variable gender, we used MANCOVAs (with the variable gender as covariate) and MANOVAs followed by univariate analyses. Multivariate analyses were performed because the correlations among the dependent variables were significant and moderate (see Table 2). As each factor is made up of more than two levels or groups, Scheffé's test was used as post hoc contrast to determine the levels between which there were significant differences.

\section{Results}

\section{Gender, Academic Goals, and Indicators of Learning Quality}

First, analyses of mean differences were performed to determine whether men and women are significantly different with regard to the goals and indicators of learning quality. If this were the case, this should be taken into account when appraising the impact of the goals on the indicators of learning quality. In Table 3 are displayed the corresponding statistical data.

The results obtained indicated that the variable gender accounts for a significant quantity of variance both for academic goals, Wilks' $\lambda=.955, F(4,615)=7.289, p<$ $.001, \eta^{2}=.045$; and for indicators of learning quality, Wilks' $\left.\lambda=.931, F(6,613)=7.580, p<.001, \eta^{2}=.069\right)$. When observing the data corresponding to each variable individually, with regard to academic goals, we found that these differences occur in two of the four kinds of goals: learning goals, and performance-approach goals. With regard to the indicators of learning quality, we observed statistically significant differences between men and women in four of the six variables: effort regulation, task value, meta-cognitive self-regulation, and time and study environment management.

\section{Academic Goals and Indicators of Learning Quality}

Below are presented the results corresponding to the relation between the four kinds of academic goals and the indicators of learning quality.

With regard to learning goals, or task orientation, the multivariate analyses indicate a statistically significant effect of the goals, Wilks' $\lambda=.730, F(12,1222)=17.351, p<$ $.001,{ }_{-}^{2}=.146$, and the covariate gender, Wilks' $\lambda=.948$, $F(6,611)=5.632, p<.001,{ }_{-}^{2}=.052$, respectively, on the series of indicators of learning quality. The contrasts of the corresponding means (see Table 4) also revealed statistically significant differences in all the indicators of learning quality as a function of the three levels of learning goals: effort regulation, meta-cognitive self-regulation, self-efficacy for learning and performance, control-of-learning beliefs, and time and study environment management. Moreover, the post hoc contrasts revealed that the differences were significant among all the goal levels and for each indicator of learning quality, except for the control-of-learning beliefs, where no differences were found between the moderate-goal group and the high-goal group. Likewise, the same tendency was observed in all the variables: as the level of learning goals increases, the indicators of learning quality also increase.

Table 3

Descriptive statistics (means and standard deviations) of men and women in academic goals and indicators of learning quality

\begin{tabular}{|c|c|c|c|c|c|c|c|}
\hline & & \multicolumn{2}{|c|}{ Men } & \multicolumn{2}{|c|}{ Women } & \multirow{2}{*}{$F_{1,618}$} & \multirow{2}{*}{$\eta^{2}$} \\
\hline & & M & SD & M & $\mathrm{SD}$ & & \\
\hline \multirow{4}{*}{ GOALS } & Learning Goals & 3.65 & 0.83 & 3.88 & 0.69 & $12.94 * * *$ & .02 \\
\hline & Work-Avoidance Goals & 3.18 & 0.94 & 3.03 & 0.87 & 3.56 & .01 \\
\hline & Performance-Approach Goals & 2.38 & 1.00 & 2.07 & 0.93 & $13.40 * * *$ & .02 \\
\hline & Performance-Avoidance Goals & 2.55 & 1.04 & 2.63 & 0.99 & 0.72 & .00 \\
\hline \multirow{6}{*}{ INDICATORS } & Effort Regulation & 3.21 & 0.69 & 3.47 & 0.65 & $20.52 * * *$ & .03 \\
\hline & Task Value & 3.26 & 0.68 & 3.44 & 0.58 & $11.28 * * *$ & .02 \\
\hline & Meta-cognitive Self-Regulation & 3.26 & 0.51 & 3.52 & 0.48 & $35.32 * * *$ & .05 \\
\hline & Self-Efficacy for Learning and Performance & 3.30 & 0.62 & 3.32 & 0.56 & 0.15 & .00 \\
\hline & Control-of-learning beliefs & 3.42 & 0.69 & 3.47 & 0.61 & 1.01 & .00 \\
\hline & Time and Study Environment Management & 3.26 & 0.55 & 3.50 & 0.52 & $26.89 * * *$ & .04 \\
\hline
\end{tabular}

Note. Score range for academic goals and indicators of learning quality: $1=$ never, $2=$ practically never, $3=$ sometimes, $4=$ almost always, 5 = always.

$* \mathrm{p}<.05 . * * \mathrm{p}<01 * * * \mathrm{p}<.001$ 
Table 4

Indicators of learning quality in relation to different levels of learning goals (controlling the effect of gender)

\begin{tabular}{|c|c|c|c|c|c|c|c|c|}
\hline \multirow{3}{*}{ Learning Quality Indicators } & \multicolumn{6}{|c|}{ Learning Goals } & \multirow{3}{*}{$F_{1,618}$} & \multirow{3}{*}{$\eta^{2}$} \\
\hline & \multicolumn{2}{|c|}{ Low Goals } & \multicolumn{2}{|c|}{ Moderate Goals } & \multicolumn{2}{|c|}{ High Goals } & & \\
\hline & $M$ & $S D$ & $M$ & $S D$ & $M$ & $S D$ & & \\
\hline Effort regulation & 3.07 & 0.70 & 3.39 & 0.57 & 3.71 & 0.65 & $40.23 * * *$ & .12 \\
\hline Task value & 2.98 & 0.65 & 3.45 & 0.48 & 3.70 & 0.56 & $72.77 * * *$ & .19 \\
\hline Meta-cognitive self-regulation & 3.14 & 0.53 & 3.46 & 0.39 & 3.69 & 0.46 & $60.10 * * *$ & .16 \\
\hline Self-efficacy for learning and performance & 3.07 & 0.59 & 3.35 & 0.55 & 3.50 & 0.52 & $30.12 * * *$ & .09 \\
\hline Control-of-learning beliefs & 3.25 & 0.71 & 3.53 & 0.58 & 3.56 & 0.58 & $13.97 * * *$ & .04 \\
\hline Time and study environment management & 3.18 & 0.56 & 3.45 & 0.46 & 3.63 & 0.50 & $32.82 * * *$ & .10 \\
\hline
\end{tabular}

$* \mathrm{p}<.05 . * * \mathrm{p}<01 * * * \mathrm{p}<.001$.

${ }^{\text {a }}$ gender is a covariate

With regard to work-avoidance goals (see Table 5), both the kind of goal and the variable gender (covariate) significantly accounted for the variability observed in the indicators of learning quality, Wilks' $\lambda=.898, F(12,1222)$ $=5.611, p<.001, \eta^{2}=.052$, and Wilks' $\lambda=.934, F(6$, $616)=7.215, p<.001, \eta^{2}=.066$, respectively. Controlling the effect of the variable gender, statistically significant differences were also observed for each one of the indicators of learning quality - except for control-of-learning beliefsas a function of the levels of this type of goals: effort regulation, task value, meta-cognitive self-regulation, selfefficacy for learning and performance, and time and study environment management. The general tendency was that the higher the level of work-avoidance goals, the lower the indicators of learning quality. The post hoc contrasts indicated that in effort regulation, task value, and metacognitive self-regulation, there were significant differences among all the goal groups, whereas in self-efficacy for learning and performance and in time and study environment management, there were only significant differences between the high-goal group and the low-goal and moderate-goal groups.

Concerning performance-approach goals, as in the other two cases, both gender and the level of goals revealed a significant effect on the indicators of learning quality, Wilks' $\lambda=.939, F(6,611)=6.670, p<.001, \eta^{2}=.061$, and Wilks' $\lambda=.953, F(12,1222)=2.458, p<.01, \eta^{2}=$ .024 , respectively. The data provided by the ANCOVAs for each indicator of learning quality only revealed statistically significant differences for task value, and meta-cognitive self-regulation as a function of the levels of the goals. Although in the post hoc contrasts, there were significant differences among the high-goal group compared to the other two groups, the tendency observed was that as the levels in this goal increase, the value assigned to academic tasks decreases, as does metacognitive self-regulation (see Table 6). There were no significant differences in the remaining indicators of learning quality as a function of the levels of performanceapproach goals.

Table 5

Indicators of learning quality in relation to different levels of work-avoidance goals (controlling the effect of gender)

\begin{tabular}{|c|c|c|c|c|c|c|c|c|}
\hline \multirow{3}{*}{ Learning Quality Indicators } & \multicolumn{6}{|c|}{ Work-Avoidance Goals } & \multirow{3}{*}{$F_{2,616^{a}}$} & \multirow{3}{*}{$\eta^{2}$} \\
\hline & \multicolumn{2}{|c|}{ Low Goals } & \multicolumn{2}{|c|}{ Moderate Goals } & \multicolumn{2}{|c|}{ High Goals } & & \\
\hline & $M$ & $S D$ & $M$ & $S D$ & $M$ & $S D$ & & \\
\hline Effort regulation & 3.59 & 0.63 & 3.41 & 0.64 & 3.11 & 0.71 & $20.52 * * *$ & .06 \\
\hline Task value & 3.55 & 0.67 & 3.38 & 0.52 & 3.18 & 0.68 & $13.35^{* * *}$ & .04 \\
\hline Meta-cognitive self-regulation & 3.59 & 0.50 & 3.41 & 0.43 & 3.28 & 0.56 & $15.69 * * *$ & .05 \\
\hline Self-efficacy for learning and performance & 3.38 & 0.58 & 3.34 & 0.51 & 3.17 & 0.66 & $5.73 * *$ & .02 \\
\hline Control-of-learning beliefs & 3.46 & 0.66 & 3.46 & 0.57 & 3.45 & 0.70 & 0.02 & .00 \\
\hline Time and study environment management & 3.54 & 0.51 & 3.45 & 0.49 & 3.23 & 0.57 & $14.76 * * *$ & .05 \\
\hline
\end{tabular}

Note. ${ }^{\mathrm{a}}$ gender is a covariate

$* \mathrm{p}<.05$. ** $\mathrm{p}<01 * * * \mathrm{p}<.001$. 
Table 6

Indicators of learning quality in relation to different levels of work-avoidance goals (controlling the effect of gender)

\begin{tabular}{|c|c|c|c|c|c|c|c|c|}
\hline \multirow{3}{*}{ Learning Quality Indicators } & \multicolumn{6}{|c|}{ Performance-Approach Goals } & \multirow{3}{*}{$F_{2,616^{a}}$} & \multirow{3}{*}{$\eta^{2}$} \\
\hline & \multicolumn{2}{|c|}{ Low Goals } & \multicolumn{2}{|c|}{ Moderate Goals } & \multicolumn{2}{|c|}{ High Goals } & & \\
\hline & $M$ & $S D$ & $M$ & $S D$ & $M$ & $S D$ & & \\
\hline Task value & 3.48 & 0.60 & 3.40 & 0.56 & 3.25 & 0.72 & $4.96^{* *}$ & .02 \\
\hline Meta-cognitive self-regulation & 3.50 & 0.46 & 3.46 & 0.46 & 3.31 & 0.57 & $4.49 *$ & .01 \\
\hline Self-efficacy for learning and performance & 3.31 & 0.56 & 3.30 & 0.51 & 3.32 & 0.69 & 0.02 & .00 \\
\hline Control-of-learning beliefs & 3.48 & 0.63 & 3.50 & 0.54 & 3.37 & 0.76 & 1.94 & .01 \\
\hline Time and study environment management & 3.43 & 0.52 & 3.42 & 0.50 & 3.43 & 0.59 & 0.43 & .00 \\
\hline
\end{tabular}

Note. ${ }^{\mathrm{a}}$ gender is a covariate

$* \mathrm{p}<.05 . * * \mathrm{p}<01 * * * \mathrm{p}<.001$.

Table 7

Indicators of learning quality in relation to different levels of performance-avoidance goals (controlling the effect of gender)

\begin{tabular}{|c|c|c|c|c|c|c|c|c|}
\hline \multirow{3}{*}{ Learning Quality Indicators } & \multicolumn{6}{|c|}{ Performance-Avoidance Goals } & \multirow{3}{*}{$F_{2,616^{a}}$} & \multirow{3}{*}{$\eta^{2}$} \\
\hline & \multicolumn{2}{|c|}{ Low Goals } & \multicolumn{2}{|c|}{ Moderate Goals } & \multicolumn{2}{|c|}{ High Goals } & & \\
\hline & $M$ & $S D$ & $M$ & $S D$ & $M$ & $S D$ & & \\
\hline Effort regulation & 3.43 & 0.72 & 3.35 & 0.63 & 3.39 & 0.68 & 0.53 & .00 \\
\hline Task value & 3.47 & 0.67 & 3.38 & 0.60 & 3.34 & 0.61 & 2.55 & .01 \\
\hline Meta-cognitive self-regulation & 3.55 & 0.54 & 3.38 & 0.45 & 3.41 & 0.49 & $6.60 * * *$ & .02 \\
\hline Self-efficacy for learning and performance & 3.48 & 0.62 & 3.34 & 0.47 & 3.21 & 0.59 & $10.75^{* * *}$ & .03 \\
\hline Control-of-learning beliefs & 3.60 & 0.63 & 3.44 & 0.57 & 3.40 & 0.66 & $5.64 * *$ & .02 \\
\hline Time and study environment management & 3.42 & 0.55 & 3.42 & 0.56 & 3.43 & 0.51 & 0.03 & .00 \\
\hline
\end{tabular}

Note. ${ }^{\mathrm{a}}$ gender is a covariate.

$* \mathrm{p}<.05 . * * \mathrm{p}<01 * * * \mathrm{p}<.001$.

And lastly, gender and performance-avoidance goals also revealed statistically significant effects on the indicators of learning quality, Wilks' $\lambda=.931, F(6,611)=7.590, p<.001$, $\eta^{2}=.069$, and Wilks' $\lambda=.944, F(12,1224)=2.956, p<.001$, $\eta^{2}=.028$, respectively. With regard to the specific quality learning indicators, statistically significant differences were found in meta-cognitive self-regulation, self-efficacy for learning and performance, and control-of-learning beliefs as a function of the different levels of performance-avoidance goals. For the other three variables, the differences were nonsignificant. The post hoc contrasts revealed statistically significant differences between the low-goal group and the other two groups. In this particular case, the tendency was that as the level of performance-avoidance goals increases, self-efficacy for learning and performance, meta-cognitive self-regulation, and controlof-learning beliefs decrease (see Table 7).

\section{Discussion}

The results found show that the indicators of learning quality contemplated herein are positively related to adopting learning goals or task orientation.
As learning goal levels increase, the levels of all the indicators considered also increase. Therefore, students with higher levels of this type of motivational orientation will show more persistence (effort regulation), will place more value on academic tasks and activities, be more capable of self-regulating their learning, manage time better, and will present higher self-efficacy and beliefs of control over learning.

These results are partially in accordance with those provided by other studies carried out with university students, which reported positive relations of learning goals with effort and persistence (e.g., Elliot et al., 1999), and also a positive influence, mediated by deep processing strategies, of learning goals on effort (e.g., Bandalos et al., 2003). Likewise, Wolters (2004) also found-in this case with secondary students-that learning goals positively predict effort and persistence. In the same line as these results, students who believed that their ability to learn can be improved or enhanced through effort and experience over time were more likely than their peers to maintain both intrinsic and extrinsic goal orientations, appreciate the value of learning tasks, feel confident about their current ability to learn, and perceive an internal locus of control over their learning (Paulsen \& 
Feldman, 2005). Moreover, these students also use more frequently elaboration and organization strategies, time and study environment management, meta-cognitive selfregulation strategies, and effort regulation, among other strategies (Paulsen \& Feldman, 2007).

As expected, in the case of work-avoidance goals, the opposite pattern is observed. The high levels of these goals in the students, the lower their persistence, the value they assign to academic tasks, their degree of self-regulation, self-efficacy, and time management.

Similar results were observed in the case of performance goals, although in the case of performance-approach goals, the results only show significant differences in the assigned task value and in meta-cognitive self-regulation. Concerning performance-avoidance goals, significant differences in the levels of these goals were only found in self-regulation, selfefficacy, and beliefs of control over learning. It seems clear that, in both types of performance goals, the significant results follow the same tendency as in the case of workavoidance goals, that is, the higher the levels of these goals, the lower the indicators of learning quality.

The results of this study show that, at least in the university setting, only the motivational orientation in which the desire and concern to learn and increase knowledge and capacities in a certain area are predominant is positively related to the learning quality levels characterized by the high value assigned to academic tasks, high persistence and self-efficacy, strong beliefs in control over learning, and a high capacity of self-regulation and time management.

In the remaining motivational orientations (workavoidance goals and performance goals - of either approach or avoidance), having low, moderate, or high levels of these kind of goals is either irrelevant and, therefore, has no incidence on learning quality, or else the relation is negative, so that high levels in these motivational orientations are accompanied by the lowest levels in some of the indicators of learning quality contemplated in this study.

In this sense, to a good extent, the results of this study corroborate the argument proposed by Midgley, Kaplan, and Middleton (2001) when they say that the revision of the theory of goals is not a priority issue because the most generalized postulate is still to consider learning goals as adaptive and performance goals as maladaptive. In fact, in the case of performance-approach goals, where the results are more divergent, the problem surfaces when these goals can potentially become performance-avoidance goals, which can occur when students' experiences of perceived competence or likelihood of failure change (Kaplan \& Maehr, 2007; Middleton, Kaplan, \& Midgley, 2004).

However, as revealed in this paper, even though only learning goals are positively related to quality learning, it is still necessary to clarify many issues, particularly those referring to performance-approach goals and their role in the learning process, aspects that are still controversial and divergent when contrasting diverse studies.
With regard to this and other aspects, some limitations in this study can be observed, which could constitute possible starting points for future investigations in this area.

Firstly, it could be very interesting to address this same goal but with groups of subjects whose motivational profiles are the result of combining the different types of goals (i.e., configured by cluster analysis) instead of using groups of goals (high, medium, low). Empirical research seems to indicate that many students choose several goals at once, which are responsible for the students' engagement in the learning tasks. Thus, in situations in which the learning activity is not very stimulating or interesting, reasons other than intrinsic interest in the task may be useful to motivate students' performance. In these cases, the possibility to choose for different reasons-getting others' approval, winning prizes and external rewards, etc.—can become a powerful incentive to promote and maintain academic commitment (Valle et al., 2007). Therefore, the fact that students may choose several goals simultaneously in concrete school situations could be one of the most beneficial options at an academic level.

For example, Barron and Harackiewicz (2001) have suggested four ways in which learning goals and performance-approach goals could be combined. The first way would be that in which both types of goals are combined, but each one has beneficial effects for certain results, that is, their effects are additive. A second possible explanation is that the effects of both types of goal are interactive, so that adopting both types of goals at the same time is more adaptive for a certain result than only adopting one type of goal. The third possibility is that the effects are specialized, that is, there are unique effects for both types of goals over multiple results; for example, mastery goals are beneficial in terms of interest or emotional well-being, whereas performance-approach goals are adaptive for results such as achievement. And, lastly, these authors suggest the possibility of selective effects, so that the consequences of effects of the goals depend on whether or not they coincide with the goals of the context.

Secondly, we should take the data from this investigation with some caution because they were obtained by means of multivariate analysis of variance and covariance techniques (MANOVAs and MANCOVAs) on data obtained from a nonexperimental design. Although this procedure is very frequent in psychoeducational research, the analysis of the relation between both groups of variables (goals and indicators of learning quality) through structural equation models (preferably with latent variables) would be germane.

And thirdly, taking into account the gender differences revealed by past research, although in this investigation we attempted to control the effect of this variable statistically, introducing it in the analysis as a covariate, in the future, it would be an excellent strategy to consider it as an independent variable in a block design. Thus, it would be 
possible to determine the effect of the goals and of gender in particular, as well as the interaction of these variables in the explanation of the variability of the dependent variables (indicators of learning quality).

\section{References}

Anderman, E. M., \& Wolters, C. (2006). Goals, values and affects: Influences on student motivation. In P. Alexander \& P. Winne (Eds.) Handbook of educational psychology (2 ${ }^{\text {nd }}$ ed.) (pp. 369390). New York: Simon and Schuster.

Anderman, E. M., \& Young, A. J. (1994). Motivation and strategy use in science: Individual differences and classroom effects. Journal of Research in Science Teaching, 31, 811-831.

Archer, J. (1994). Achievement goals as a measure of motivation in university students. Contemporary Educational Psychology, 19, 430-446.

Bandalos, D., Finney, S., \& Geske, J. (2003). A model of statistics performance based on achievement goal theory. Journal of Educational Psychology, 95,604-616.

Barron, K. E., \& Harackiewicz, J. M. (2001). Achievement goals and optimal motivation: Testing multiple goals models. Journal of Personality and Social Psychology, 80, 706- 722.

Brdar, I., Rijavec, M., \& Loncaric, D. (2006). Goal orientations, coping with school failure and school achievement. European Journal of Psychology of Education, 21, 53-70.

Dupeyrant, C., \& Mariné, C. (2005). Implicit theories of intelligence, goal orientation, cognitive engagement, and achievement: A test of Dweck's model with returning to school adults. Contemporary Educational Psychology, 30, 43-59.

Elliot, A. J. (1999). Approach and avoidance motivation and achievement goals. Educational Psychologist, 34, 169-189.

Elliot, A. J. (2005). A conceptual history of the achievement goal construct. In A. J. Elliot \& C. S. Dweck (Eds.), Handbook of competence and motivation (pp. 52-72). New York: Guilford Press.

Elliot, A. J., \& Church, M. A. (1997). A hierarchical model of approach and avoidance achievement motivation. Journal of Personality and Social Psychology, 72, 218-232.

Elliot, A. J., McGregor, H. A., \& Gable, S. (1999). Achievement goals, study strategies, and exam performance: A mediational analysis. Journal of Educational Psychology, 91, 549-563.

Elliot, A. J., \& Moller, A. C. (2003). Performance-approach goals: Good or bad forms of regulation? International Journal of Educational Research, 39, 339-356.

Greene, B. A., DeBacker, T. K., Ravindran, B., \& Krows, A. J. (1999). Goals, values, and beliefs as predictors of achievement and effort in high school mathematics classes. Sex Roles, 40, 421-458.

Harackiewicz, J. M., Barron, K. E., Carter, S. M., Letho, A. T., \& Elliot, A. J. (1997). Predictors and consequences of achievement goals in the college classroom: Maintaining interest and making the grade. Journal of Personality and Social Psychology, 73, 1284-1295.
Harackiewicz, J. M., Barron, K. E., \& Elliot, A. J. (1998). Rethinking achievement goals: When are they adaptive for college students and why? Educational Psychologist, 33, 1-21.

Harackiewicz, J. M., Barron, K. E., Pintrich, P. R., Elliot, A. J., \& Thrash, T. (2002). Revision of achievement goal theory: Necessary and illuminating. Journal of Educational Psychology, 94, 638-645.

Harackiewicz, J. M., Barron, K. E., Tauer, J. M., Carter, S. M., \& Elliot, A. J. (2000). Short-term and long-term consequences of achievement goals: Predicting interest and performance over time. Journal of Educational Psychology, 92, 316- 330.

Kaplan, A., \& Maehr, M. L. (2007). The contributions and prospects of goal orientation theory. Educational Psychology Review, 19, 141-184.

Lens, W., \& Vansteenkiste, M. (2008). Promoting self-regulated learning. A motivational analysis. In D. H. Schunk \& B. J. Zimmerman (Eds.), Motivation and self-regulated learning. Theory, research, and applications (pp. 141-168). New York: LEA.

Meece, J. L., Anderman, E. M., \& Anderman, L. H. (2006). Classroom goal structure, student motivation and academic achievement. Annual Review of Psychology, 57, 487-503.

Meece, J.L., Glienke, B. B., \& Burg, S. (2006). Gender and motivation. Journal of School Psychology, 44, 351-373.

Meece, J. L., \& Jones, G. (1996). Gender differences in motivation and strategy use in science: Are girls rote learners? Journal of Research on Science Teaching, 33, 407-431.

Middleton, M., Kaplan, A., \& Midgley, C. (2004). The change in middle school students' achievement goals in math over time. Social Psychology of Education 7, 289-311.

Middleton, M., \& Midgley, C. (1997). Avoiding the demonstration of lack of ability: An unexplored aspect of goal theory. Journal of Educational Psychology, 89, 710-718.

Midgley, C., Kaplan, A., \& Middleton, M. (2001). Performanceapproach goals: Good for what, for whom, under what circumstances, and at what cost? Journal of Educational Psychology, 93, 77-86.

Nicholls, J. G., Pastashnick, M., \& Nolen, S. B. (1985). Adolescents' theories of education. Journal of Educational Psychology, 76, 683-692.

Paulsen, M. B., \& Feldman, K. A. (2005). The conditional and interaction effects of epistemological beliefs on the selfregulated learning of college students: Motivational strategies. Research in Higher Education, 46, 731-768.

Paulsen, M. B., \& Feldman, K. A. (2007). The conditional and interaction effects of epistemological beliefs on the selfregulated learning of college students: Cognitive and behavioral strategies. Research in Higher Education, 48, 353-401.

Pintrich, P. R., Marx, R.W., \& Boyle, R. (1993). Beyond 'cold' conceptual change: The role of motivational beliefs and classroom contextual factors in the process of conceptual change. Review of Educational Research, 63, 167-199.

Pintrich, P. R., Smith, D. A., Garcia, T., \& McKeachie, W. J. (1991). A manual for the use of the Motivated Strategies for Learning Questionnaire (MSLQ). Ann Arbor, MI, National Center for Research to Improve Postsecondary Teaching and Learning. 
Rodríguez, S., Cabanach, R. G., Piñeiro, I., Valle, A., Núñez, J. C., \& González-Pienda, J. A. (2001).Approach goals, avoidance goals and multiple academic goals. Psicothema, 13, 546-550.

Skaalvik, E. (1997). Self-enhancing and self-defeating ego orientation: Relations with task and avoidance orientation, achievement, self-perceptions, and anxiety. Journal of Educational Psychology, 89 71-81.

Thorkildsen, T. A. \& Nicholls, J. G. (1998). Fifth-graders' achievement orientations and beliefs: Individual and classroom differences. Journal of Educational Psychology, 90, 179-201.

Utman, C. (1997). Performance effects of motivational state: A meta-analysis. Personality and Social Psychology Review, 1, 170-182.

Valle, A., Cabanach, R. G., Rodríguez, S., Núñez, J. C., \& González-Pienda, J. A. (2006). Academic goals, cognitive and self-regulatory strategies. Psicothema, 18, 166-170.

Valle, A., Cabanach, R.G., Rodríguez, S., Núñez, J.C., GonzálezPienda, J.A., Solano, P., \& Rosário, P. (2007). A motivational perspective on the self-regulated learning in higher education. In P.B. Richards (Ed.), Global issues in higher education (pp. 99-125). New York: Nova Science Publishers.
Wolters, C. (2004). Advancing achievement goal theory: Using goal structures and goal orientations to predict students' motivation, cognition, and achievement. Journal of Educational Psychology, 96, 236-250.

Wolters, C. A., Yu, S. L., \& Pintrich, P. R. (1996). The relation between goal orientation and students' motivational beliefs and self-regulated learning. Learning and Individual Differences, 8, 211-238.

Zimmerman, B. J. (2008). Goal setting: A key proactive source of academic self-regulation. In D. H. Schunk \& B. J. Zimmerman (Eds.), Motivation and self-regulated learning. Theory, research, and applications (pp. 141-168). New York: LEA.

Zimmerman, B. J., \& Schunk, D. H. (2008). Motivation. An essential dimension of self-regulated learning. In D. H. Schunk \& B. J. Zimmerman (Eds.), Motivation and self-regulated learning. Theory, research, and applications (pp. 141-168). New York: LEA.

Received September 30, 2007 Revision received July 6, 2008 Accepted September 9, 2008 